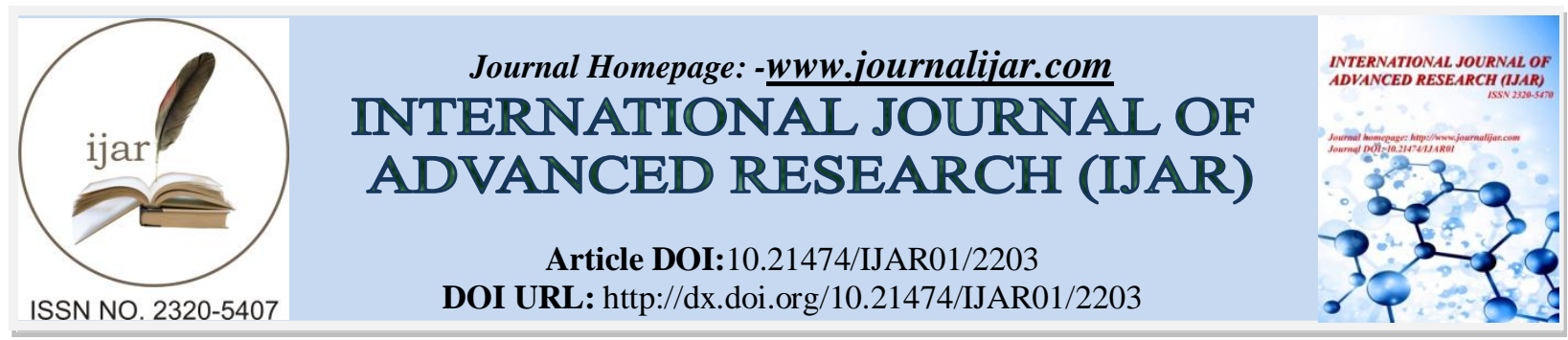

RESEARCH ARTICLE

\title{
HAND GRIP STRENGTH AS A NUTRITIONAL ASSESSMENT TOOL IN PATIENTS WITH LIVER CIRRHOSIS.
}

\author{
Shaimaa Elkholy, Sherif Mogawer, Mona Mansour, Reem Elmessiery and Ahmed Elmeligui \\ Internal medicine department, Faculty of Medicine, Cairo University.
}

\section{Manuscript Info}

Manuscript History

Received: 28 September 2016

Final Accepted: 30 October 2016

Published: November 2016

Key words:-

Liver cirrhosis - nutrition- hand grip strength.

\section{Abstract}

Background: -Protein energy malnutrition (PEM) is a recognized complication in patients with liver cirrhosis; most randomized studies have shown a significant increase in morbidity and mortality in relation to its severity. Yet, there is no gold standard method for nutritional assessment of these patients up till now.

Aim of the work: - the aim of this study is to assess the efficacy of hand grip strength as a nutritional assessment tool and its sensitivity and specificity in detecting PEM.

Methods: -This is a case control study that was designed to analyze data from 78 Egyptian patients with CHILD C liver cirrhosis. Subjective global assessment (SGA), anthropometric tools, hand grip strength (HGS) were used to assess the nutritional status of these patients. It also included 50 healthy volunteers with matched age, gender and area of residence.

Results: - Severe PEM was prevalent among the patients; HGS was highly correlated to the degree of malnutrition ( $\mathrm{p}$-value $=0.008$ ). ROC curve analysis showed a criterion of 17.6 with specificity $90 \%$ and sensitivity of $60 \%$.

Conclusion:- PEM is prevalent among patients with cirrhosis. Nutritional assessment in decompensated patients remains a challenge for clinicians. HGS is a simple, bed side tool that can be used to assess the muscle status and can be used in a complementary manner with other methods for proper assessment of the patients.

Copy Right, IJAR, 2016,. All rights reserved.

\section{Introduction:-}

Protein energy malnutrition (PEM) is a common complication among patients with liver cirrhosis (1); most randomized studies have shown a significant increase in morbidity and mortality in relation to its severity ${ }^{(2)}$. PEM is found in a bout $60-90 \%$ and $20 \%$ of decompensated and compensated liver cirrhosis respectively ${ }^{(3)}$.In liver transplantation, PEM has been reported in almost $100 \%$ of patients prior to transplantation ${ }^{(4)}$. Malnourishment was found to be an independent risk factor for morbidity and mortality in recipients following liver transplantation ${ }^{(5)}$. Nutritional assessment of patients with liver cirrhosis has its limitations; this is due to the fact that conventional methods used for assessment of malnutrition are not useful in cirrhotic patients ${ }^{(6)}$. For example, body mass index (BMI) is not a reliable method in such patients due to the presence of ascites and edema that will cause an increase the measured weight; whereas the lean body mass might actually be reduced ${ }^{(6)}$. Also, some of the commonly used 
laboratory parameters that are used to indicate the nutritional status such as albumin and pre-albumin concentrations are not reliable in patients with cirrhosis due to defective synthesis rather than malnutrition, besides they are considered as negative acute phase reactants ${ }^{(7)}$. Yet, there is no gold standard method for nutritional assessment for these patients up till now ${ }^{(8)}$.

\section{Patients and methods:-}

\section{Study design:-}

This study is a case control study that was designed to analyze data from seventy eight Egyptian patients with CHILD C liver cirrhosis of different etiologies, both inpatients and patients on regular follow up at the outpatient clinic. This study was conducted at KasrAlainy hospital, Internal Medicine Department, Faculty of Medicine - Cairo University. It included 45 males $(57.7 \%)$ and 33 females (42.3\%), their age ranged from 28 to 70 yearswith mean $56.5 \pm 9.3$. The study also included a control group of fifty healthy volunteers of age, sex and area of residence matched individuals. The control group included 30(60\%) males and 20(40\%) females, with mean age 50.32 \pm 9.43.

All patients included in the study were subjected to the following: Thorough history taking, full clinical examination, laboratory tests and full nutritional assessment including anthropometric measurements such as body mass index (BMI), triceps skin fold thickness (TST) and mid arm circumference (MAC). Subjective global assessment (SGA) was also used, upon which our patients were classified into mild, moderate and severely malnourished. Hand grip strength was measured in the patients and the control groups.

\section{Random assignment (Inclusion criteria):-} All patients fulfilled the following Inclusion Criteria:-

Patients with liver cirrhosis classified as Child C according to Child-Turcott-Pug scoring system ${ }^{(9)}$ presented with or without complications of liver cirrhosis (e.g. acute variceal bleeding, hepatic encephalopathy, hepatorenal syndrome or with spontaneous bacterial peritonitis). The diagnosis of liver cirrhosis was based on clinical, laboratory and ultra sonographic criteria.

Our Exclusion criteria were patients with other negative catabolic status as:-

- Patients with carcinomas e.g. HCC, cholangiocarcinoma etc.

- Other chronic diseases as chronic renal failure, HTN, heart failure, etc.

- Patients with systemic inflammatory response syndrome or septic shock.

- Patients with joint disabilities as rheumatoid arthritis, SLE or any other joint disease were excluded from the study.

\section{Thorough history taking and clinical examination:-}

The patients were subjected to full history taking and clinical examination(including full neurological examination) with focusing on the following points that were fulfilled for SGA:

- History of unexplained weight loss during the last six months and they were categorized according to the percentage of loss into three categories.Cat1: $<5 \%$ loss, Cat2: 5\%-10\% loss and Cat3: $>10 \%$ loss.

- Dietary intake changes (relative to normal) during the last six months either being normal, suboptimal liquid diet, full liquid diet, hypocaloric liquids or starvation.

- Functional capacity during the last six months as regarding being normal (full capacity), working suboptimally, ambulatory or bedridden.

- $\quad$ Presence of persistent GIT symptoms in the last 2 weeks in the form of nausea, vomiting, anorexia and diarrhea.

The patients were subjected to full clinical examination with stressing on the following points that were fulfilled for SGA:-

- Loss of subcutaneous fat in chest and triceps regions

- Muscle wasting in quadriceps and deltoid regions.

- $\quad$ Presence of oedema (ascites, lowerlimb, sacral oedema).

Then patients were classified according to SGA into mild, moderate and severely malnourished. 


\section{Laboratory Tests:-}

The following laboratory tests were done to the patient mainly for assessing their liver condition and to select the CHILD C category. They were in the form of CBC, LFTs, KFTs, coagulation profile and lipid profile. Fasting blood sugar and oral glucose tolerance test were done.

\section{Anthropometric measures:-}

Body Mass Index (BMI):-

BMI was calculated twice considering actual (measured) and dry (calculated) body weight. Dry body weight is subjective estimation of a patient's weight without ascites or lower limb edema ${ }^{(10)}$. It was calculated according to the degree of ascites and existence of LL edema as following:

- In the presence of mild ascites we subtract $5 \%$ of actual body weight.

- In the presence of moderate ascites we subtract $10 \%$ of actual body weight.

- In the presence of tense ascites we subtract $15 \%$ of actual body weight.

- In the presence of lower limb edema with any degree of ascites we subtract additional $5 \%$ of actual weight.

\section{TSFT and MAC:-}

Triceps skin fold thickness and mid arm circumference were measured in the non-dominant arm mid-way between acromion and olecranon process then mid arm circumference measured by tape while triceps skin fold thickness was measured by skin folder.

\section{Hand Grip strength (HGS):-}

It was measured using the hand grip dynamometry shown in Figure (1). The patient's data in the form of age and sex were entered then the patient was asked to use their maximum effort to grip both handles of the dynamometer together. The test was repeated for 3 times for each hand separately then the highest record value was used as an indicator of patient's performance. Then the results were compared with the normal values for age and sex and this will be provided as a supplement in a separate file.

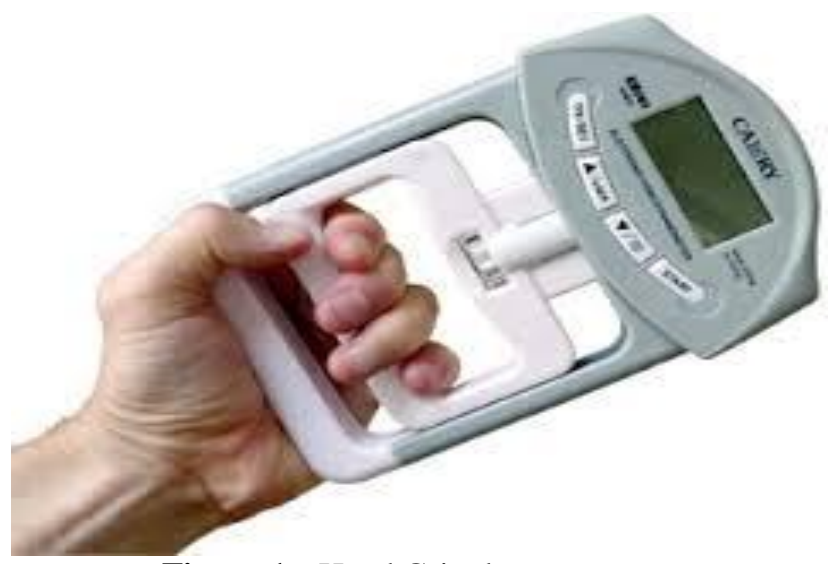

\section{Compliance with the study:-}

Figure 1:- Hand Grip dynamometer.

The patients were $100 \%$ compliant to the study.

\section{Statistical analysis:-}

Data were statistically described in terms of mean \pm standard deviation $( \pm \mathrm{SD})$, median and range, or frequencies (number of cases) and percentages when appropriate. Comparison of numerical variables between the study groups was done using one way analysis of variance (ANOVA) test with post-hoc multiple 2-group comparisons. For comparing categorical data, Chi square $\left(\chi^{2}\right)$ test was performed. Exact test was used instead when the expected frequency is less than 5. Correlation between various variables was done using Spearman rank correlation equation for non-normal variables/non-linear monotonic relation. All statistical calculations were done using computer program SPSS (Statistical Package for the Social Science; SPSS Inc., Chicago, IL, USA) release 20 for Microsoft Windows (2010). P $>0.05$ was considered not significant, $\mathrm{P}<0.05$ statistically significant and $\mathrm{P}<0.001$ highly significant. 


\section{Results:-}

Incidence of complications among the patients:-

The study showed that $39(50 \%)$ of our patients presented with SBP, 65(83.3\%) with hepatic encephalopathy and 50(64\%) with GIT bleeding as shown in figure (2). It also showed that all the patients had ascites, $45(57.6 \%)$ had moderate ascites while $33(42.3 \%)$ had severe ascites. Fifty four $(69.9 \%)$ of the patients had impaired glucose tolerance while $22(28.2 \%)$ patients developed frank diabetes.

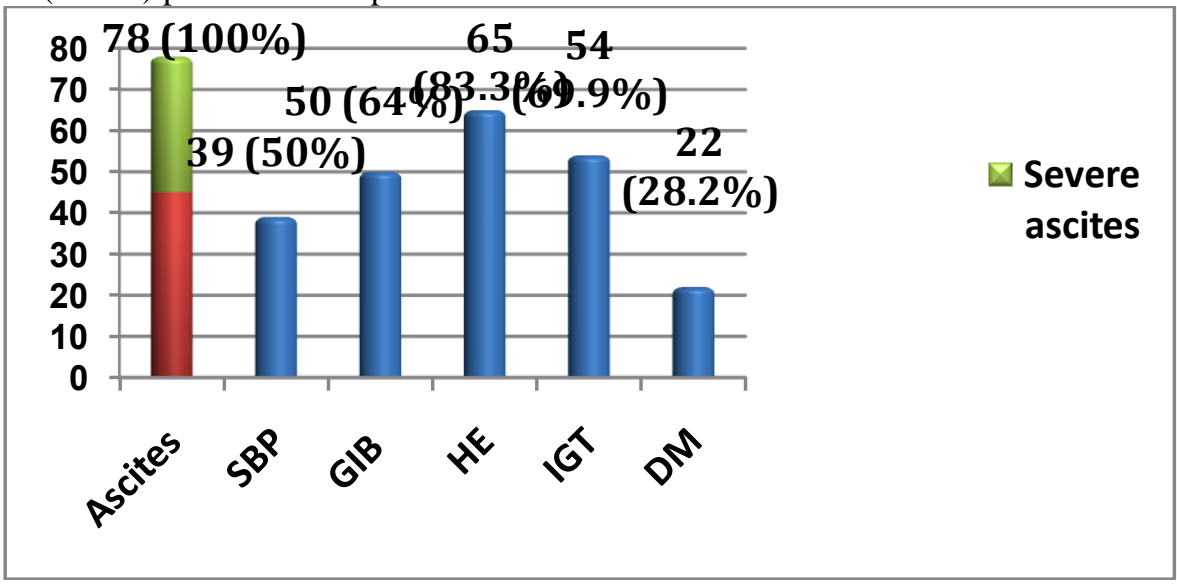

Figure 2:- Rate of complications among patients with liver cirrhosis

\section{Different degree of PEM among our patients:-}

Patients with mild degree of malnutrition were 16 (20.5\%) while those with moderate degree were $26(33.3 .8 \%)$ and those with severe degree were $36(46.2 \%)$.

\section{Anthropometric measures of the patient:-}

The mean BMI measured in the patients according to Dry body weight was about 25. $6 \pm 5.7$ SD while BMI calculated according to actual body weight showed mean $30.6 \pm 7.1 \mathrm{SD}$ as shown in table (1). Both didn't show any statistically significant difference among various degrees of malnutrition (p-value 0.07 ).

Table 1:- Anthropometric measurements of the patients

\begin{tabular}{|c|c|}
\hline Variable & Results \\
\hline $\begin{array}{l}\text { BMI according to : } \\
\text { Dry weight }\end{array}$ & $\begin{array}{l}\text { Mean } \pm \text { SD } \\
25.6 \pm(5.7)\end{array}$ \\
\hline Actual weight & $30.6 \pm(7.1)$ \\
\hline $\begin{array}{l}\text { Mid Arm Circumference Percentiles: } \\
\text { Below } 5^{\text {th }}\end{array}$ & $\begin{array}{l}\text { Number }(\%) \\
48(61.5 \%)\end{array}$ \\
\hline & $1(1.3 \%)$ \\
\hline Between $5-10^{\text {th }}$ & $6(7.7 \%)$ \\
\hline $10^{\text {th }}$ & $1(1.3 \%)$ \\
\hline Between $10-25^{\text {th }}$ & $5(6.4 \%)$ \\
\hline $25^{\text {th }}$ & $3(3.8 \%)$ \\
\hline Between $25-50^{\text {th }}$ & $8(10.3 \%)$ \\
\hline Between $50-75^{\text {th }}$ & $1(1.3 \%)$ \\
\hline Between $75-90^{\text {th }}$ & $5(6.4 \%)$ \\
\hline Triceps Skin Fold Thickness Percentiles: & Number (\%) \\
\hline Below $5^{\text {th }}$ & $22(28.2 \%)$ \\
\hline & $5(6.4 \%)$ \\
\hline Between $5-10^{\text {th }}$ & $6(7.7 \%)$ \\
\hline & $3(3.8 \%)$ \\
\hline Between $10-25^{\text {th }}$ & $6(7.7 \%)$ \\
\hline $25^{\text {th }}$ & $4(4.4 \%)$ \\
\hline Between $25-50^{\text {th }}$ & $25(32.1 \%)$ \\
\hline $50^{\text {th }}$ & $2(2.6 \%)$ \\
\hline Between $50-75^{\text {th }}$ & $3(3.8 \%)$ \\
\hline $75^{\text {th }}$ & $1(1.3 \%)$ \\
\hline $95^{\text {th }}$ & $1(1.3 \%)$ \\
\hline
\end{tabular}

(SD): standard deviation, BMI: body mass index. 
MAC ranged from $17 \mathrm{~cm}$ to $34 \mathrm{~cm}$ with mean $24.7 \pm 3.6 \mathrm{SD}$ and $48(61.5 \%)$ of the patients were below the $5^{\text {th }}$ percentile curve as shown in table (1). MAC was correlated significantly to the degree of PEM with correlation coefficient -0.49 using spearman's correlation and p-value $=0.0001$ as shown in table (2).

Table 2:-Relationship between TSFT \& MAC and the degree of PEM

\begin{tabular}{|l|l|l|r|}
\hline \multicolumn{2}{|c|}{ PEM } & -0.28 \\
\hline \multirow{4}{*}{ Spearman's rho } & \multirow{2}{*}{ TSFT } & Correlation Coefficient & 0.014 \\
\cline { 3 - 4 } & & Sig (2-tailed) & 78 \\
\cline { 2 - 3 } & N & -0.49 \\
\cline { 2 - 4 } & \multirow{2}{*}{ MAC } & Correlation Coefficient & 0.0001 \\
\cline { 3 - 4 } & & Sig (2-tailed) & 78 \\
\cline { 3 - 4 } & & N & \\
& &
\end{tabular}

TSFT ranged from $0.2 \mathrm{~cm}$ to $2.5 \mathrm{~cm}$ with mean $1.07+0.66 \mathrm{SD}$ and $22(28.2 \%)$ of the patients were below the $5^{\text {th }}$ percentile while $25(32.1 \%)$ were between $25^{\text {th }}$ and $50^{\text {th }}$ percentiles curve as shown in table (1).TSFT was significantly correlated to the degree of PEM with correlation coefficient -0.28 using spearman's correlation and $\mathrm{p}$ value (p-value 0.014 ) as shown in table (2).

\section{HGS measurement among patients:-}

Handgrip strength was found to be normal in 4 patients (5.2\%) and weak in 74 patients (94.8\%). Weak hand grip of the right hand ranged from $6.5 \mathrm{~kg}$ to $35 \mathrm{~kg}$ with mean $18.9 \pm 7.5 \mathrm{SD} \mathrm{kg}$ with $95 \%$ confidence interval of the mean that lies between $(16.7-21.2)$ but for the weak left hand it ranged from $5.5 \mathrm{~kg}$ to $38 \mathrm{~kg}$ with mean $17.9 \pm 7.5 \mathrm{SD} \mathrm{kg}$ with $95 \%$ confidence interval of the mean that lies between $(15.6-20.1)$ as shown in table (3).

Table 3:- Handgrip strength measurements of the patients

\begin{tabular}{|c|c|c|c|c|c|c|}
\hline \multirow{2}{*}{$\begin{array}{l}\text { HGS } \\
\text { in } \mathrm{kg}\end{array}$} & \multirow[t]{2}{*}{$\mathbf{N}(\%)$} & \multirow[t]{2}{*}{ Min } & \multirow[t]{2}{*}{$\operatorname{Max}$} & \multirow[t]{2}{*}{ Mean \pm SD } & \multicolumn{2}{|c|}{ 95\% CI for Mean } \\
\hline & & & & & $\begin{array}{l}\text { Lower } \\
\text { Bound }\end{array}$ & $\begin{array}{l}\text { Upper } \\
\text { Bound }\end{array}$ \\
\hline Weak Left & $74(94.8 \%)$ & 5.5 & 38.0 & $17.9 \pm 7.52$ & 15.6 & 20.1 \\
\hline Weak Right & $74(94.8 \%)$ & 6.5 & 35 & $18.9 \pm 7.5$ & 16.7 & 21.2 \\
\hline Normal Left & $4(5.2 \%)$ & 19.1 & 45.4 & $29.5 \pm 12.3$ & 9.9 & 49.1 \\
\hline Normal Right & $4(5.2 \%)$ & 19.2 & 45.5 & $29.8 \pm 12.2$ & 10.3 & 49.28 \\
\hline
\end{tabular}

HGS: hang grip strength, SD: standard deviation, CI: confidence interval, $\mathrm{N}$ : number

Table (4) is across tabulation between HGS and degree of PEM that shows that all patients (100\%) with moderate and severe malnutrition had weak HGS. While 4 (25\%) of the patients with mild malnutrition had normal HGS, and 12 (75\%) of the patients with mild malnutrition had weak HGS as shown.

Table 4:-Cross tabulation that shows HGS among different degrees of malnutrition.

\begin{tabular}{|l|l|c|c|c|c|}
\hline \multicolumn{2}{|c|}{} & \multicolumn{3}{c|}{ PEM } & \multirow{2}{*}{ Total } \\
\cline { 3 - 6 } \multicolumn{2}{|c|}{} & $\begin{array}{c}\text { Mild } \\
\text { N (\%) }\end{array}$ & $\begin{array}{c}\text { Moderate } \\
\text { N }(\%)\end{array}$ & $\begin{array}{c}\text { Severe } \\
\text { N }(\%)\end{array}$ & \\
\hline \multirow{2}{*}{ HGS } & Normal & $4(25 \%)$ & 0 & 0 & 4 \\
& Weak & $12(75 \%)$ & $26(100 \%)$ & $36(100 \%)$ & 74 \\
\hline \multicolumn{2}{|l|}{ Total } & $16(100 \%)$ & $26(100 \%)$ & $36(100 \%)$ & 78 \\
\hline
\end{tabular}

$\mathrm{N}$ : number, PEM: protein energy malnutrition, HGS: hand grip strength

Table (5) showed a significant correlation between HGS and PEM (p-value $=0.008$ ) using chi-square tests. Also HGS was significantly correlated to PEM that showed correlation coefficient of -0.357 and -0.505 to HGS of the right and left hand respectively with p- value of 0.001 and 0.000 of the right and left hand respectively using spearman's correlation as shown in table (6). ROC curve analysis showed a criterion of 17.6 with specificity $90 \%$ and sensitivity of $60 \%$ as shown in figure (3). 


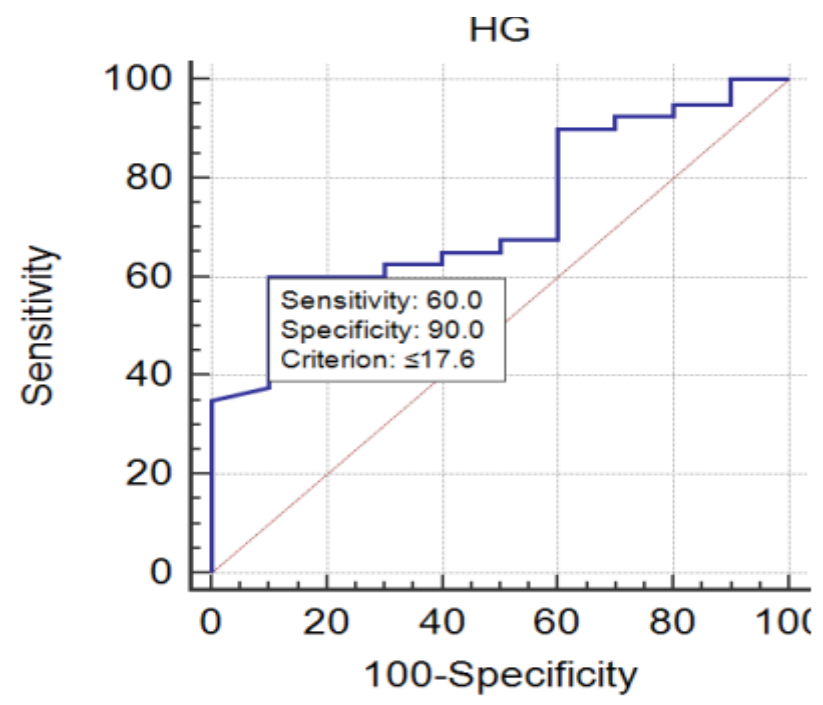

Figure 3:- ROC curve analysis between hand grip strength (HGS) and protein energy malnutrition (PEM).

Table 5:-Relationship between HGS and degree of PEM using Chi-square tests

\begin{tabular}{|l|c|c|c|}
\hline & Value & df & P value \\
\hline Pearson Chi-Square & 16.338 & 2 & 0.000 \\
\hline Likelihood Ratio & 13.56 & 2 & 0.001 \\
\hline Linear-by-Linear Association & 10.934 & 1 & 0.001 \\
\hline N of Valid Cases & 78 & & \\
\hline
\end{tabular}

Table 6:-spearman correlation between HGS and PEM

\begin{tabular}{|l|l|l|c|}
\hline \multirow{3}{*}{ Spearman's rho } & \multirow{2}{*}{ HGSRT } & Correlation coefficient & PEM \\
\cline { 3 - 4 } & & Sig (2-tailed) & -0.375 \\
\cline { 2 - 3 } & Number & 0.001 \\
\cline { 2 - 3 } & \multirow{3}{*}{ HGSLT } & Correlation coefficient & -0.505 \\
\cline { 3 - 4 } & & Sig (2-tailed) & 0.000 \\
\cline { 3 - 4 } & Number & 78 \\
\hline
\end{tabular}

HGSRT: hand grip strength of the right hand, HGSLT: hand grip strength of the left hand, PEM: protein energy malnutrition

Relationship between HGS and other nutritional assessment tools:-

By comparing HGS with other anthropometric tools; it showed no significant correlation with BMI according to dry body weight, BMI according to actual body weight, TSFT and MAC as shown in table (7).

Table 7:-correlation between HGS and other anthropometric measures.

\begin{tabular}{|l|l|c|c|c|c|}
\hline \multicolumn{2}{|c|}{} & TSFT & MAC & $\begin{array}{c}\text { BMI for Dry } \\
\text { weight }\end{array}$ & $\begin{array}{c}\text { BMI for Actual } \\
\text { Weight }\end{array}$ \\
\hline \multirow{2}{*}{ HGSRT } & Pearson Correlation & -0.274 & -0.03 & -0.06 & -0.115 \\
\cline { 2 - 6 } & Sig. (2-tailed) & 0.15 & 0.793 & 0.601 & 0.316 \\
\hline HGSLT & Pearson Correlation & -0.306 & -0.042 & -0.141 & -0.176 \\
\hline
\end{tabular}

HGSRT: hand grip strength of the right hand, HGSLT: hand grip strength of the left hand, TSFT: triceps skin fold thickness, MAC: mid arm circumference, BMI: body mass index

\section{Sensitivity and specificity of HGS:-}

The sensitivity and specificity of HGS regarding prediction of moderate to severe malnutrition were 100\% and $40 \%$ respectively along with PPV and NPV of $86.9 \%$ and $100 \%$ respectively, as well as accuracy of $88 \%$.

Relation between MELD (model of end stage liver disease) score and various nutritional assessment tools:MELD score showed no significant correlation with HGS with correlation coefficient $=-0.09$ and P-value of 0.53. Also did not show any significance with other nutritional assessment tools. 


\section{Linear regression for HGS:-}

As shown in table (9) by regression analysis for HGS; it was found that PEM was significantly related to HGS with P-value of 0.03 with B coefficient of -0.27 with $95 \%$ confidence interval that lies between $(-5.2$ to -0.27$)$. Also age was significantly correlated to HGS. While MAC had a border line significant of $\mathrm{p}$-value $=0.052$.

Table 9:- Multiple linear regression analysis of HGS.

\begin{tabular}{|l|c|c|c|c|}
\hline Model for HGS & Beta Coefficient & \multirow{2}{*}{ Sig. } & \multicolumn{2}{|c|}{ 95 \% Confidence Interval } \\
\cline { 3 - 5 } & & & Lower Bound & Upper Bound \\
\hline PEM & -0.27 & 0.030 & -5.221 & -0.27 \\
\hline TSFT & -0.66 & 0.3 & -11.781 & 4.144 \\
\hline MAC & 0.353 & 0.052 & -0.007 & 1.538 \\
\hline Age & -0.318 & 0.003 & -0.446 & -0.094 \\
\hline Serum albumin & 0.149 & 0.151 & -0.875 & 5.542 \\
\hline Total proteins & 0.127 & 0.204 & -0.678 & 3.114 \\
\hline A/G RATIO & -0.021 & 0.836 & -3.668 & 2.977 \\
\hline MELD & 0.084 & 0.415 & -0.234 & 0.561 \\
\hline
\end{tabular}

PEM: protein energy malnutrition, TSFT: triceps skin fold thickness, MAC: mid arm circumference, A/G ratio: albumin/globulin ration, MELD: model of end stage liver disease.

\section{Characteristics of the control group:-}

This study included 50 healthy volunteers; $30(60 \%)$ males and 20(40\%) females, with mean age 50.32 \pm 9.43 . As shown in table (8) there is a highly significant difference regarding MAC, TSFT and HGS between the control group and the patients group.

Table 8:-Differences between the control group and the patients group

\begin{tabular}{|c|c|c|c|c|}
\hline & Mean & SD & $\mathbf{t}$ & $\begin{array}{l}\text { Sig (2-tailed) } \\
\text { P-value }\end{array}$ \\
\hline BMI of the patients according to dry weight & 24.7 & 5.4 & \multirow[t]{2}{*}{-3.6} & \multirow[t]{2}{*}{0.001} \\
\hline BMI of the control group & 29.2 & 5.6 & & \\
\hline $\begin{array}{l}\text { BMI of the patients according to actual } \\
\text { weight }\end{array}$ & 29.56 & 6.77 & \multirow[t]{2}{*}{0.245} & \multirow[t]{2}{*}{0.808} \\
\hline BMI of the control group & 29.22 & 5.64 & & \\
\hline MAC of the patients & 24.5 & 3.4 & \multirow[t]{2}{*}{-5.68} & \multirow[t]{2}{*}{0.000} \\
\hline MAC of the control group & 28.98 & 3.48 & & \\
\hline TSFT of the patients & 1.014 & 0.63 & \multirow[t]{2}{*}{-5.22} & \multirow[t]{2}{*}{0.000} \\
\hline TSFT of the control group & 1.72 & 0.6 & & \\
\hline HGS of the patients & 19.8 & 8.43 & \multirow[t]{2}{*}{-8.4} & \multirow[t]{2}{*}{0.000} \\
\hline HGS of the control group & 36.3 & 10.07 & & \\
\hline
\end{tabular}

SD: standard deviation

\section{Discussion:-}

PEM is a common complication among patients with liver cirrhosis that ranges from about $20 \%$ in compensated liver disease to $65 \%-100 \%$ in decompensated liver cirrhosis. PEM has been reported in up to $100 \%$ of the patients on the waiting liver transplant list ${ }^{(9)}$. It is considered to be an independent risk factor for morbidity and mortality among those patients. For patients with compensated cirrhosis; many randomized trials have showed that they are more likely to be similar to a healthy population regarding clinical and laboratory background ${ }^{(\mathbf{1 0})}$. The problem remains for the decompensated cirrhotic patients who are the target population of this study. Standard nutritional assessment tools have limitations when applied to patients with decompensated cirrhosis.

Using the conventional nutritional assessment methods such as measuring body weight and BMI have shown to be less reliable in the assessment of patients with ascites due to their false increase in the body weight ${ }^{(6)}$. This was also shown in our study even when calculating the estimated dry body weight; still it showed no significant correlation as shown above.

SGA is a simple evaluation tool that was the corner stone in the evaluation of the nutritional status of our patients. It has the advantage of allowing the physicians to incorporate clinical findings and subjective patient history into a nutritional assessment. Its efficacy has been tested in many studies and its use as a reference method is quiet

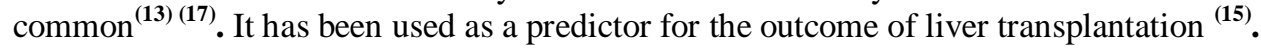


Anthropometric tests as MAC or TSFT have shown a good estimate of the patients' nutritional status and their efficacy had been proved by many studies ${ }^{\left({ }^{(13)}\right.}$.Mogawer et al showed that TSFT and MAC was highly correlated to the degree of PEM and also considered as predictors of complications among patients with liver cirrhosis ${ }^{(\mathbf{1 6})}$. As shown in table (2) MAC and TSFT had a significant correlation with PEM with p value $<0.0001$ and 0.014 . TSFT is a good estimate of the fat composition of the body but doesn't reflect the muscle bulk or strength that could be measured by other methods as HGS ${ }^{(20)}$.

ESPEN (European Society for Parenteral and Enteral Nutrition) guidelines (2006) on liver disease recommended the use of simple bedside methods such as the SGA or anthropometry to identify patients at risk of under nutrition ${ }^{(\mathbf{1 7})}$.

PEM is well known to include caloric deficiency, alteration of the fat components, muscle loss, macro, micro nutrients deficiency and even effect on bone metabolism ${ }^{(23)}$. But our main concern was for muscle bulk for which HGS could be its representative ${ }^{(6)}$.

Hand grip Strength (HGS) is a noninvasive, simple and quick method that can be used in clinical and epidemiological studies that may be very useful in decompensated cirrhosis since malnourished patient present with lean mass depletion and low muscle strength. It measures the combined action of a large number of muscles as well as the combined action of a number of different joints ${ }^{(17)}$. By comparing outcome with normative data, of intrinsic and extrinsic hand muscles as well, the amount of muscle strength loss can be determined. Muscle bulk or strength can be a very accurate estimate for the protein malnutrition in the patients with cirrhosis ${ }^{(18)}$. Total serum protein and serum albumin have failed among many studies to be correlated to the degree of PEM and this was also proven in with our study. This may be due to the fact that albumin is a negative acute phase reactant that may be decreased is stressful conditions besides that the defective synthesis due to hepatic impairment ${ }^{(\mathbf{1 9})}$. Mogawer et al tried to assess the muscle bulk status using especial body fat monitor but it showed insignificant results ${ }^{(16)}$.

So, by estimating the muscle power using HGS it could override the defect in estimating the protein malnutrition in cirrhotic patients. As shown in our results that 74 out of 78 patients have impaired HGS with highly significant correlation to the degree of PEM ( $\mathrm{p}$-value $<0.0001$ ).

By performing regression analysis for HGS it confirmed the presence of causal effect with PEM with P-value of 0.03 and B coefficient of -0.27 with $95 \%$ confidence interval that lies between (-5.2 to -0.27$)$. Also showed a border line significant correlation with MAC (p-value of 0.052) which seems to be logic as MAC also showed significant correlation to PEM. But for TSFT it didn't show significant correlation even when we used Lin's concordance correlation as shown in table (7) and this may be due to the fact that each tool of them reflects a separate entity of the components of PEM.

The sensitivity and specificity of HGS regarding prediction of moderate to severe malnutrition were 100\% and 40\% respectively along with PPV and NPV of $86.9 \%$ and $100 \%$ respectively, as well as accuracy of $88 \%$.

MELD score which is the model of end stage liver disease that was implemented in the year 2002 which constitutes bilirubin, creatinine and INR (international normalized ratio) is used for assessment of the severity of liver disease and to prioritize patients with end stage liver disease ESLD on waiting list of liver transplant ${ }^{(21)}$. HGS showed a negative correlation with MELD score but didn't show significant $\mathrm{p}$-value. Waheed et al also showed a good correlation between HSG with Child-Turcott-Pug scoring system but not with the MELD score ${ }^{(22)}$.

However; HGS had been tested in many trails not only in cirrhotic patients but also for detecting early changes in muscle function and correlating well with nutritional status, in the surgical word ${ }^{(25)}$.

Currently, The European Working Group on Sarcopenia in Older People (EWGSOP) recommends measurement of handgrip strength as a practical measure of muscle strength ${ }^{(24)}$.

To conclude, PEM has a significant impact on the outcome of patients with liver cirrhosis. Nutritional assessment in decompensated cirrhotic patients remains a challenge for the clinicians. Nutritional assessment tools such as anthropometric tests as MAC and TSFT remains on the top of the list. HGS is a noninvasive, simple and quick method that can be used in clinical and epidemiological studies. These dynamometer measurements could have a more sensitive change compared to manual muscle testing and thus rendering the prediction of the outcome on a 
continuous scale. A composite of SGA, Anthropometry and HGS can be used in a complementary manner to accurately identify the nutritional status of patients with liver disease.

\section{Conflict of interest:}

The authors whose names are listed above certify that they have NO conflict of interest with any organization or entity with any financialor non-financial interest in the subject matter or materials discussed in this manuscript.

\section{References:-}

1. Caregaro L, Alberino F, Amodio P, et al. Malnutrition in alcoholic and virus related cirrhosis. Am J ClinNutr 1996; 63:602609.

2. McCullough AJ, Raguso C. Effect of cirrhosis on energy expenditure. J ClinNutr 1999; 69:1066-1068.

3. Moriwaki H. Nutritional assessment in liver cirrhosis. J Gastroenterol 2006; 41:511.

4. DiCecco SR et al. Assessment of nutritional status of patients with end-stage liver disease undergoing liver transplantation. Mayo Clin Proc1989; 64: 95-102.

5. Cabré E, Gassull MA. Nutritional and metabolic issues in cirrhosis and liver transplantation. CurrOpinClinNutrMetab Care 2000; $3: 345$.

6. Anne S Henkel and Alan L Buchman. Nutritional Support in Chronic Liver Disease.NatClinPractGastroenterolHepatol. 2006; 3(4):202-209.

7. Prijatmoko D et al. Early detection of protein depletion in alcoholic cirrhosis: role of body composition analysis. Gastroenterology 1993; 105: 1911-1914.

8. NehaBakshi and Kalyani Singh. Nutrition assessment in patients undergoing liver transplant. Indian J Crit Care Med. 2014 Oct; 18(10): 672-681.

9. Pugh RN, Murray-Lyon IM, Dawson JL, et. al. Transection of the oesophagus for bleeding oesophagealvarices. Br J Surg. 1973; 60:646.

10. PuneetaTandon, Michael Ney, Ivana Irwin et al. Severe Muscle Depletion in Patients on the Liver Transplant Wait List: Its Prevalence and Independent Prognostic Value. LIVER TRANSPLANTATION 2012; 18:1209-1216.

11. Muller MJ, Boker KH, Selberg O. Are patients with liver cirrhosishypermetabolic. Clinical Nutrition, 1994; 13:131-144

12. Merli M, Nicolini G, Angeloni S, Riggio O. Malnutrition is a risk factor in cirrhotic patients undergoing surgery. Nutrition. 2002; 18:978-86.

13. Alvares-da-Silva MR, Reverbel da Silveira T. Comparison between handgrip strength, subjective global assessment, and prognostic nutritional index in assessing malnutrition and predicting clinical outcome in cirrhotic outpatients. Nutrition $2005 ; 21: 113$.

14. Pikul J et al. Degree of preoperative malnutrition is predictive of postoperative morbidity and mortality in liver transplant recipients. Transplantation 1994: 57: 469-472

15. Gunsar F, Raimondo ML, Jones S, Terreni N, Wong C, Patch D, et al. Nutritional status and prognosis in cirrhotic patients. Aliment PharmacolTher. 2006; 24:563-72.

16. Mogawer S, Mansour M, Elkholy S, et al , significance of nutrition assessment and nutrition screening in determining nutrition status and predicting complications among patients with liver cirrhosis. Modern Medicine. 2013 Apr, Vol 30

17. Plauth M, Cabré E, Riggio O, Assis-Camilo M, et al. ESPEN Guidelines on Enteral Nutrition: Liver disease. ClinNutr. 2006 Apr; 25(2):285-94.

18. Schlüssel MM1, dos Anjos LA, de Vasconcellos MT, etal.Reference values of handgrip dynamometry of healthy adults: a population-based study.Clinical Nutrition. 2008 Aug; 27(4):601-7.

19. Norman K, Stobäus N, Gonzalez MC, etal.Hand grip strength: outcome predictor and marker of nutritional status.Clinical Nutrition. 2011 Apr; 30(2):135-42.

20. Mei-Ling S Tai, Khean-Lee Goh, Siti Hawa Mohd-Taib et al. Anthropometric, biochemical and clinical assessment of malnutrition in Malaysian patients with advanced cirrhosis Nutrition Journal2010; 9:27.

21. Lladó L, Figueras J, Memba R et al. Is MELD really the definitive score for liver allocation?.LiverTranspl. 2002 Sep;8(9):795-8.

22. Waheed A. Monsef, Ibrahim Mostafa, DoaaZaky.Assessment of the Nutritional Status of the Egyptian Patient with End Stage Liver Disease Prior to Liver Transplantation.Open Journal of Gastroenterology, 2014; 4:159-169.

23. Prijatmoko D, Strauss BJG, Lambert JR, et al. Early detection of protein depletion in alcoholic cirrhosis: role of body composition analysis. Gastroenterology 1993; 105:1839-1845.

24. A. J. Cruz-Jentoft, J. P. Baeyens, J. M. Bauer et al., "Sarcopenia: European consensus on definition and diagnosis: report of the European Working Group on Sarcopenia in Older People," Age and Ageing, vol. 39, no. 4, pp.: 2010: 412-423.

25. JunDe Zhou, Miao Wang, HaiKuan Wang et al. Comparison of two nutrition assessment tools in surgical elderly inpatients in Northern China.Nutrition Journal : 2015:14:68. 